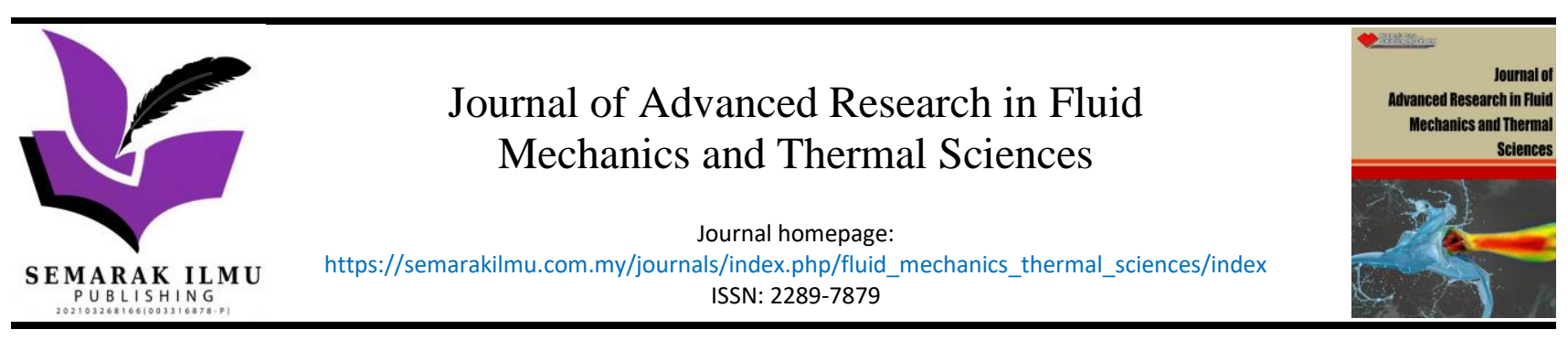

\title{
Resin Film Infusion Process: Numerical Algorithm
}

\author{
Ahmed Ouezgan ${ }^{1,}{ }^{*}$, Mouad Bellahkim $^{1}$, Said ddima $^{1}$, Aziz Maziri $^{1}$, El Hassan Mallil $^{1}$, Jamal Echaabi $^{1}$ \\ 1 Applied Research Team on Composites, Management and Innovation, High National School of Electricity and Mechanics, Hassan II University of \\ Casablanca, BP 8118, Oasis, Casablanca, Morocco
}

\section{ARTICLE INFO}

\section{Article history:}

Received 14 August 2021

Received in revised form 28 October 2021

Accepted 7 November 2021

Available online 28 December 2021

\section{Keywords:}

Liquid composite molding; resin film infusion; numerical algorithm; resin

\section{ABSTRACT}

The liquid composite molding (LCM) belongs to the composite manufacturing processes. In this family, a fabric preform material is placed into the mold cavity, and then it is impregnated with a thermosetting resin of low viscosity, until the fiber skeleton is entirely filled and finally polymerized to create a polymeric composite product. Due to its advantages, LCM has gained attention and competitiveness against other composite manufacturing processes. The resin film infusion (RFI) belongs to the LCM family, but unlike the other variants, such as resin transfer molding (RTM) and vacuum assisted resin infusion (VARI), in which the liquid resin is injected or infused into the mold cavity, the resin in the RFI process is placed into the mold cavity in the semi-cured state. Then, under pressure and temperature, the resin film will be liquefied and impregnated the fibrous reinforcement in the thickness direction. This particularity permits to RFI to fabricate large complex composite structures and reduce significantly the equipment cost as compared to the conventional resin transfer molding processes. However, as this variant used only a vacuum bag as the upper half-mold, the fabricated part has non-uniformity in the thickness, low dimensional tolerances and low fiber volume fraction. The main objective of this paper is to propose a numerical algorithm allowing to study the influence of part thickness on the RFI' filling time. Numerical simulation is based on the explicit finite difference method. The results obtained show that the filling time increases parabolically with the part thickness.

\section{Introduction}

Composite materials have gained attention and won competitiveness against other traditional metals. Recently, they have been widely applied in many fields ranging from the heavy industries, like as aeronautic, automotive and marine to the common consumer product such as sporting goods. This new high status is given to the composite materials by the virtue of their superior mechanical performance, lightweight and good resistance to corrosion and fatigue [1]. There are five major families for manufacturing composite components: autoclave, hand lay-up, filament winding, pultrusion, and liquid composite molding (LCM) [2]. Due to its capacity to significantly reduce the release of volatile organic compounds (VOCs) to the atmosphere, the LCM manufacturing processes have gained attractiveness and popularity compared with current methods of open molding

\footnotetext{
* Corresponding author.

E-mail address: ahmed.ouezgan@ensem.ac.ma
}

https://doi.org/10.37934/arfmts.90.2.2031 
processes. They have also been created to overcome the intrinsic weaknesses of autoclave draping processes such as high tooling cost and long cycle time. The term LCM refers to composite manufacturing processes in which a fibrous preform material is placed into a mold cavity and a thermosetting resin with a relatively low viscosity is impregnated the preform until all empty spaces between the fibers are filled, and finally cured to create a polymeric composite structure [3]. The LCM family encompasses a growing list of mold filling process variants distinguishable from each other by the nature of the mold used and the manner of the filling phase. The LCM mold is divided in two parts, the lower part of the mold is always rigid but the upper part is possibly be rigid, like in RTM, compression-RTM and flexible injection, semi flexible (RTM-light) or flexible such as in VARI and Liquid resin infusion (LRI), while the resin can be introduced using a combination of a positive injection pressure (use of an injection machine), vacuum infusion (use of a vacuum pump), and possibly assisted by the compaction force.

The main and the most known used LCM variant is the resin transfer molding (RTM), it was adopted for composite manufacturing in the mid-1980s [4]. RTM technique has remarkable advantages, as the two rigid halves mold are used, the process can manufacture a composite components with a good surface finish, high mechanical performance, possibility to automation and tight dimensional tolerances [5]. Despite these potentials, the resin transfer molding suffers from major weaknesses, it is unable to produce large-scale components having high fiber volume fraction. Also, the use of high injection pressure to reduce the filling time is constrained by the injection machine, mold stiffness and the fiber washing phenomenon. One approach to overcome these challenges is to replace the upper rigid half mold by a flexible vacuum bag and using only the vacuum to infuse the resin through the fabric preform. This technique is commonly known as vacuum assisted resin infusion (VARI).

In the typical VARI process, a dry fibrous preform is placed into a mold cavity, and covers by a flexible polymer film, then a sealant tape is used to adhere it to the mold in order to avoid air-resin leakage. A vacuum pump is used to evacuate the air from the cavity, which leads to compact the preform. The inlet gate is opened and resin impregnates the preform under atmospheric pressure [6]. Figure 1 illustrates a typical VARI mold components. In this process, the resin impregnation is driven by the difference between atmospheric pressure and vacuum pressure, since this pressure gradient is limited to one atmospheric pressure, the resin infiltration is very slow and the filling time increases proportional to the surface area of the manufacturing part. Moreover, as the upper rigid half mold is replaced by a flexible vacuum bag, the fabricated part has low dimensional tolerances due to the non-uniformity of part thickness, and low fiber volume fraction. Consequently, this process is not fully used in aerospace applications.

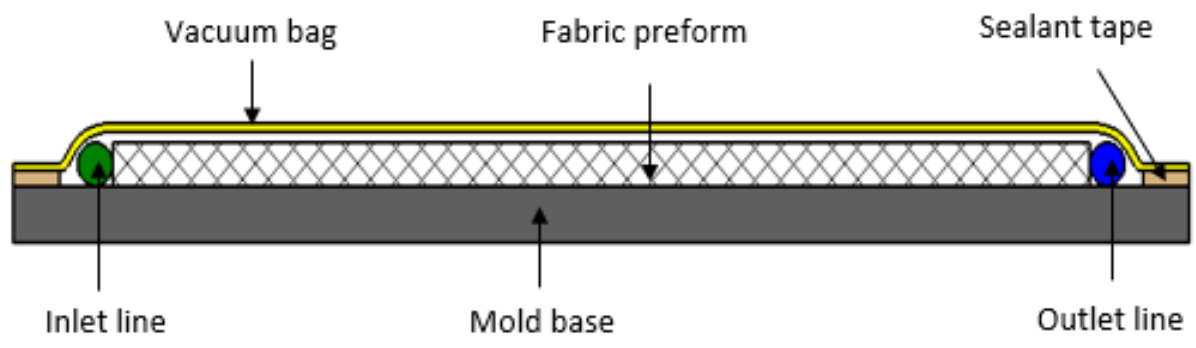

Fig. 1. A schematic of VARI mold components

The low cost of VARI process, attracting several industrial sectors such as automotive, marine and aerospace $[7,8]$, which constitutes the driven force for gaining popularity by academia. Researches are conducted in the field to fully understand and model the physical phenomena describing this process. The VARI's literature is grouped into four categories: (i) analytical formulation and closed 
form solution (ii) numerical simulation and computer code (iii) experimental approach and (iv) development of new process variants.

Compared to the existing LCM composite manufacturing techniques, the resin film infusion (RFI) process offers a significant advantages. In other liquid composite molding techniques, the liquid resin must impregnate a complex fiber part skeleton. In such cases, ensuring that the resin is evenly distributed into the fabric preform, without leaving voids or dry areas, requires a careful attention in process design, manufacturing and numerical modeling of these techniques. Also, the resin's constituents, hardener and catalyst, should properly mix in the right ratio [9]. These shortcomings are overcome by using RFI process. Although several research programs on this process were conducted by NASA, Boeing and Airbus [10] to fully describe the competing phenomena that govern the RFI process. Few articles are available in the literature, and most of them, follow experimental approaches to investigate and track the evolution of the parameters governing the resin film infusion manufacturing steps [11-13]. This is due to the strong coupling and the dependence between the four physical phenomena, rheological, thermal, chemical and mechanical that come into play in this process. In the present work, a numerical algorithm is proposed and numerical investigation is conducted to study the influence of the part thickness on the RFI' filling time.

In the simplest form of the resin film infusion process, a pre-catalyzed resin film is laid in the rigid mold base and then a dry fibrous reinforcement layers are arranged over it. The assembly is covered by a vacuum bag and adhered to it through a sealant tape. A heat source, usually an oven, is used to apply heat on the mold which melts the resin film. The melted resin impregnates the fabric preform under vacuum. Figure 2 illustrates RFI mold components.

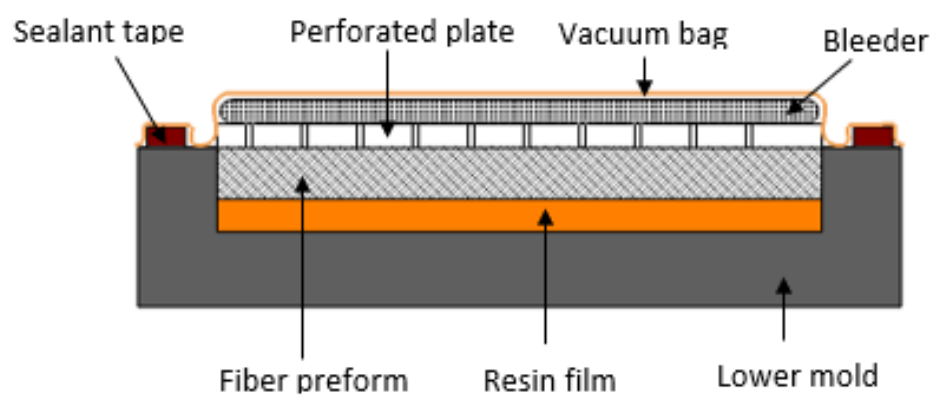

Fig. 2. RFI mold components

\section{Governing Equations}

In LCM manufacturing processes, the resin flow through a fabric preform is considered as flow through porous medium, and it is described by Darcy's law [14].

$V=-\frac{[K]}{\mu} \nabla P$

where $V$ is the volume averaged velocity, $K$ is the permeability tensor of the fibrous preform, $\nabla P$ is the resin pressure gradient, and $\mu$ is the resin viscosity.

The modeling of the physical phenomena in the liquid composite manufacturing processes are based on the concept of continuous medium [15]. The continuity equations of resin and reinforcement phases are both based on the assumptions that the two phases are incompressible and that the resin flow is saturated. In this case, the continuity equations of resin and fiber are expressed respectively

Resin phase 
$\frac{\partial\left(1-V_{f}\right)}{\partial t}+\nabla\left(\left(1-V_{f}\right) V_{r}\right)=0$

Fiber phase

$\frac{\partial V_{f}}{\partial t}+\nabla\left(V_{f} \cdot V_{s}\right)=0$

where $V_{f}$ is the fiber volume fraction, $V_{r}$ is the resin velocity and $V_{S}$ is the fiber reinforcement velocity.

Combining Eq. (2) and (3) leads to the following global continuity equation.

$\nabla V=\frac{1}{V_{f}}\left(\frac{\partial V_{f}}{\partial t}+V_{s} \nabla V_{f}\right)$

The term on the right hand side of Eq. (4) represents the volumetric change due to the relaxation or compression of fabric preform. The term $\left(\frac{1}{V_{f}} \frac{\partial V_{f}}{\partial t}\right)$ represents the volumetric change of dry preform, while the term $\left(\frac{1}{V_{f}} V_{S} \nabla V_{f}\right)$ represents the relaxation or compression of wet preform.

These terms are cancelled out in RTM process, as the result of the fixed height of the mold cavity defined by the use of the two rigid halves mold. However, the right hand side of equation should be considered in flexible or semi-flexible upper half mold, since the resin pressure in the wetted zone changes the compaction behavior of fabric preform in space and time. In the typical VARI process, the resin impregnates the fibrous reinforcement layers in the in-plane direction, while the compaction of fiber occurs in through thickness direction [16]. Accordingly, the relative velocity of fiber to resin flow can be neglected, and the second term in the RHS of Eq. (4) can be ignored. In resin film infusion process, the resin infiltration and fiber compression both occur in the transverse direction. Hence, the both terms on the RHS of equation should be considered. However, due to the slow infiltration and small fiber deformation, the second term can be ignored again.

Consequently, in one dimensional resin flow of resin film infusion process, Eq. (4) is simplified to the following form

$\frac{\partial V}{\partial z}=\frac{1}{V_{f}} \frac{\partial V_{f}}{\partial t}$

The fiber volume faction is related to the preform thickness by the following equation

$h=\frac{\rho_{A}}{\rho_{f} V_{f}}$

where $\rho_{A}$ is the area density of the fabric preform and $\rho_{f}$ is the density of the fiber filament respectively.

Terzaghi's law [17] is usually used to describe the relation between the external pressure $\sigma_{t}$ applied by the inflatable seals on the flexible membrane and the effective stress $\sigma_{f}$ exerted by the fiber reinforcement and the pressure $P$ exerted by the resin. Terzaghi's law is written as follows

$\sigma_{t}=\sigma_{f}+P$ 
The compressibility behavior of the fiber reinforcements has been described in the literature by various mathematical models. In this paper, we use the power law model [18] to describe the compaction behavior of the fabric preform.

$V_{f}=V_{f 0} \sigma_{f}^{B}$

where $V_{f 0}$ is the fiber volume fraction at $1 \mathrm{~Pa}$ and $\mathrm{B}$ is the stiffening index.

Kozeny-Carman Eq. [19] is usually utilized to describe the evolution of the permeability as function of the fiber volume fraction.

$K=K_{c} \frac{\left(1-V_{f}\right)^{3}}{\left(V_{f}\right)^{2}}$

where $K_{C}$ is the Kozeny-Carman constant.

\section{Numerical Algorithm}

In this work, a finite difference method (FDM) is employed to discretize the fabric preform into a uniform grid. This discretization is based on a first order backward discretization in space and forward Euler explicit scheme in time. The discrete difference form of Eq. (1) and (5) are written

$$
\begin{aligned}
& V_{i}^{n}=-\frac{K_{i}^{n}}{\mu}\left(\frac{P_{i+1}^{n}-P_{i-1}^{n}}{2 \Delta z}\right) \\
& \frac{V_{i}^{n}-V_{i-1}^{n}}{\Delta z}=\frac{1}{V_{f_{i}^{n}}^{n}} \frac{V_{f_{i}^{n+1}-V_{f_{i}^{n}}^{n}}}{\Delta t}
\end{aligned}
$$

where the subscript $i$ denotes the position in space and the index $\mathrm{n}$ indicates the time iteration step. This numerical method is an explicit scheme which is easy to implemented and computationally fast. However, $\Delta z$ and $\Delta t$ should carefully be chosen to ensure the stability solution. The numerical algorithm is explained in the Figure 3.

The material properties and the process parameters are listed in Table $1[20,21]$. The boundary conditions are as follows

$P=\sigma_{t}$ at the bottom of the preform.

$P=\mathrm{P}_{\text {vent }}$ at the flow front.

$\frac{\partial P}{\partial n}=0$ at the mold walls. 
Table 1

The materials properties and the process parameters

\begin{tabular}{lll}
\hline Name of parameter & Acronym & Value \\
\hline Mold cavity length & $L_{0}$ & $1 \mathrm{~m}$ \\
Resin viscosity & $\mu$ & $0.2 \mathrm{~Pa} . \mathrm{s}$ \\
Area density of preform & $\rho_{A}$ & $1 \mathrm{Kg} / \mathrm{m}^{2}$ \\
Density of fiber filament & $\rho_{f}$ & $2540 \mathrm{Kg} / \mathrm{m}^{3}$ \\
Kozeny-Carman constant & $K_{c}$ & $7.18 \times 10^{-11} \mathrm{~m}^{2}$ \\
Inlet pressure & $P_{\text {in }}$ & $95 \mathrm{KPa}, 80 \mathrm{KPa}$ \\
Vent pressure & $P_{\text {vent }}$ & $0 \mathrm{KPa}$ \\
External pressure & $\sigma_{t}$ & $101.3 \mathrm{KPa}$ \\
Compaction model constant (6 layers of NCS81053) & $\mathrm{B}$ & 0.126 \\
Compaction model constant (6 layers of NCS81053) & $V_{f 0}$ & 0.11 \\
Convergence criterion & $\varepsilon$ & $5 \times 10^{-6}$ \\
\hline
\end{tabular}

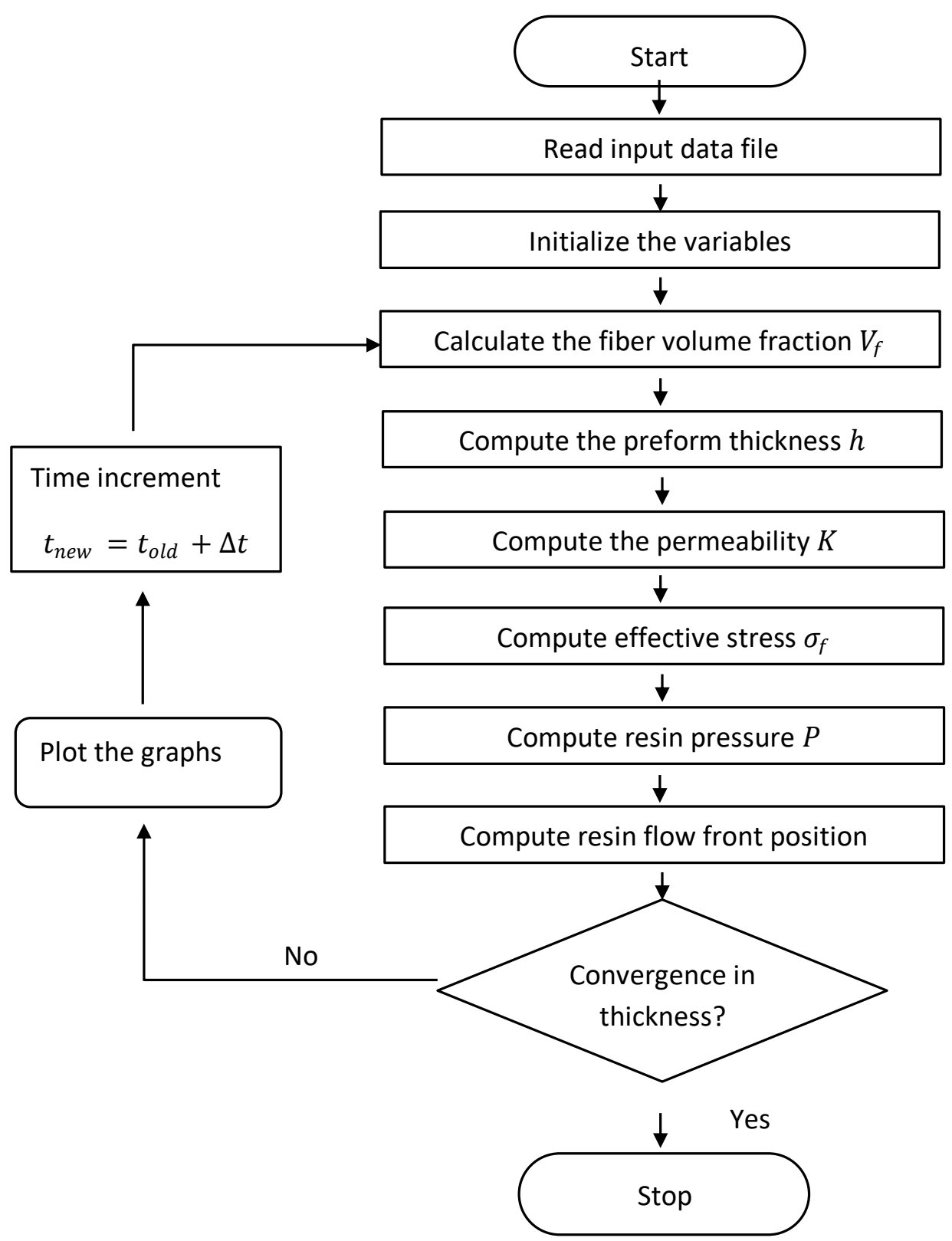

Fig. 3. RFI numerical algorithm 


\section{Results and Discussion}

To verify the validity and the stability of the present numerical scheme. A series of simulation of resin transfer molding (RTM) and traditional vacuum assisted resin infusion (VARI) process are conducted. The material properties and the processing conditions used in these simulations are the same as presented in Table 1. Then, the results obtained are compared with analytical solution for RTM and with Correia [20] and Chang [22] for VARI process. In the resin transfer molding, unlike the resin film infusion process, the part thickness is invariant during the whole manufacturing steps. In this case, the continuity equation in $x$-direction is written as follows

$$
\frac{\partial V}{\partial x}=0
$$

By combining Eq. (12) with Darcy's law, one can analytically obtain the distribution of resin pressure along the part length direction, and the evolution of flow front position with time respectively.

$$
\begin{aligned}
& P(x)=\left(\frac{P_{\text {vent }}-P_{\text {in }}}{\mathrm{L}}\right) x+\mathrm{P}_{\text {in }} \\
& L(t)=\sqrt{\frac{2 K\left(P_{\text {in }}-P_{\text {vent }}\right)}{\mu\left(1-V_{f}\right)} t}
\end{aligned}
$$

As seen in Figure 4 and in accordance with Eq. (13) the resin pressure decreases linearly from the inlet gate to the flow front position, where the resin is zero, while the flow front position is proportional to the square root of filling time, as illustrated in Figure 5.

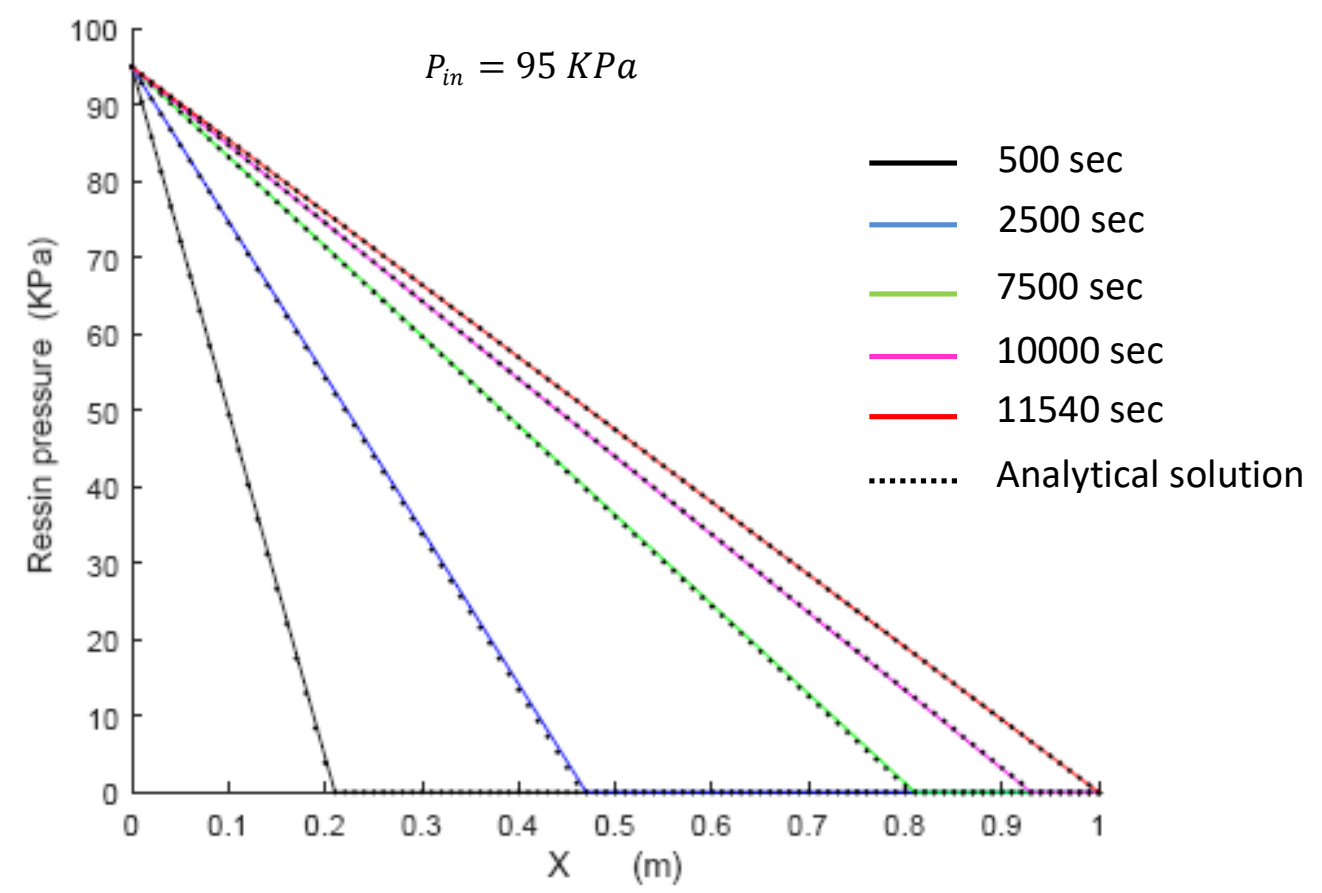

Fig. 4. Resin pressure distribution in RTM process 


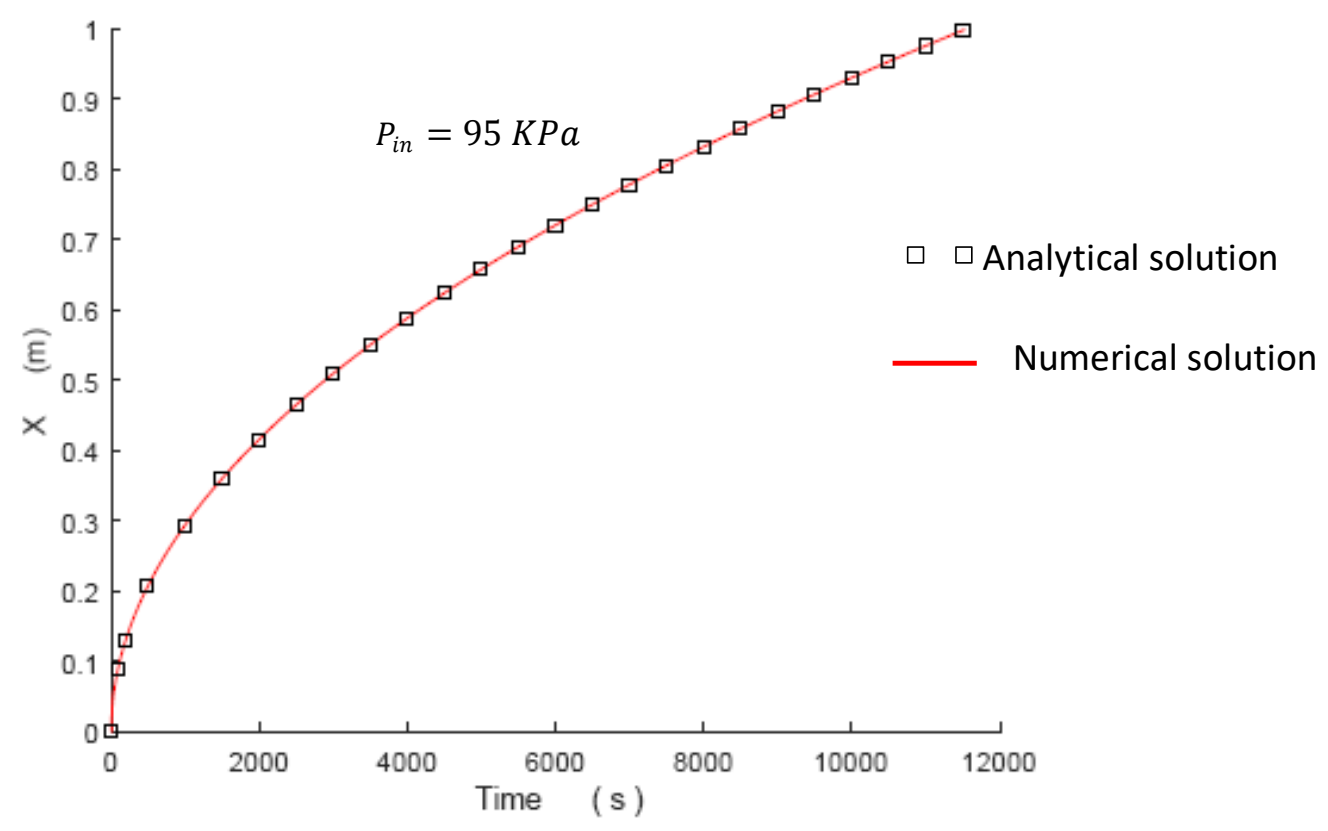

Fig. 5. Resin flow front position at various time in RTM process

It found that the results obtained by the present numerical approach have a very good agreements with those obtained from analytical formulation for RTM and the work conducted respectively by Correia and Chang for VARI process, as shown in Figures 6-9.
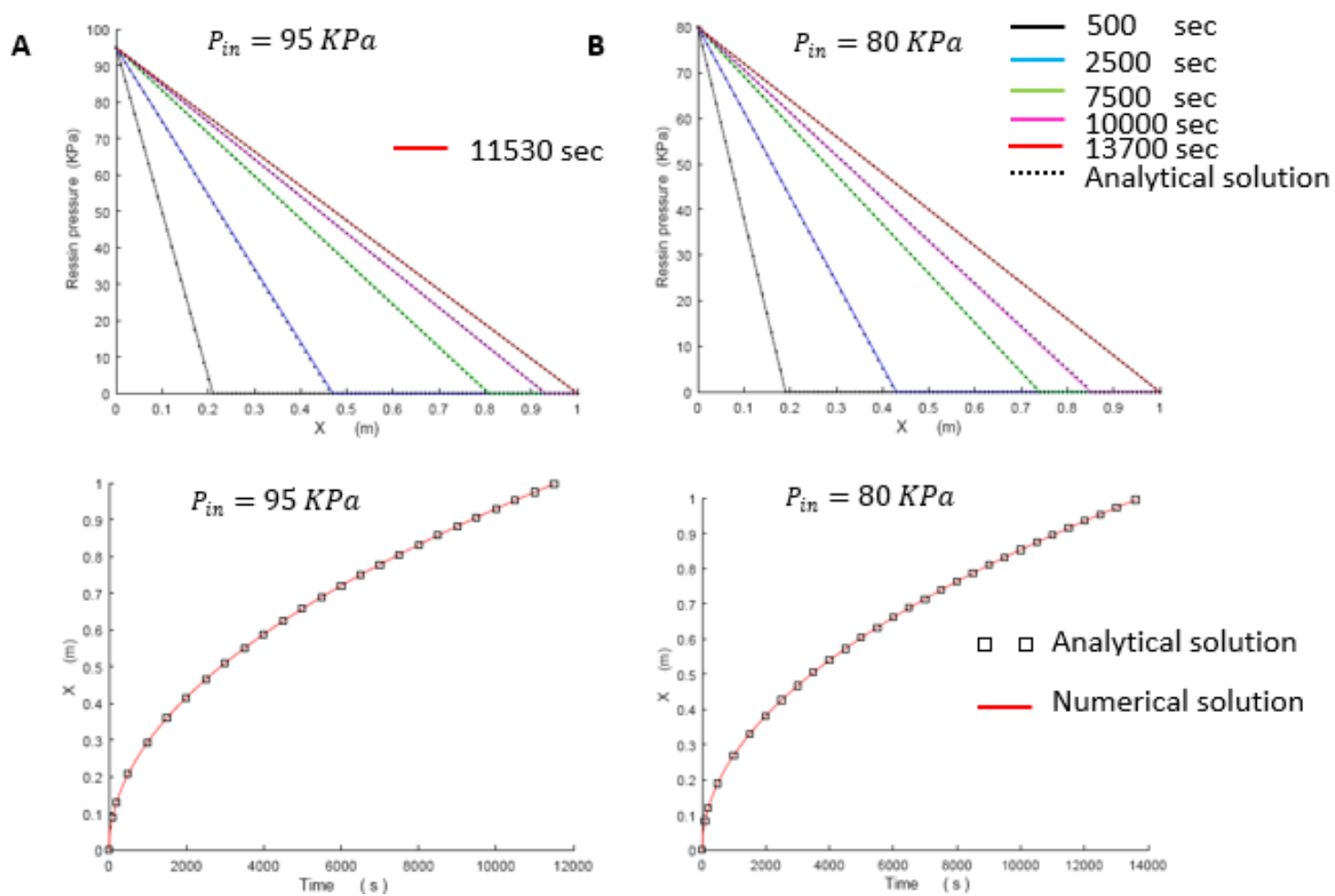

Fig. 6. Resin pressure distribution and resin progression at various injection pressure in RTM process 

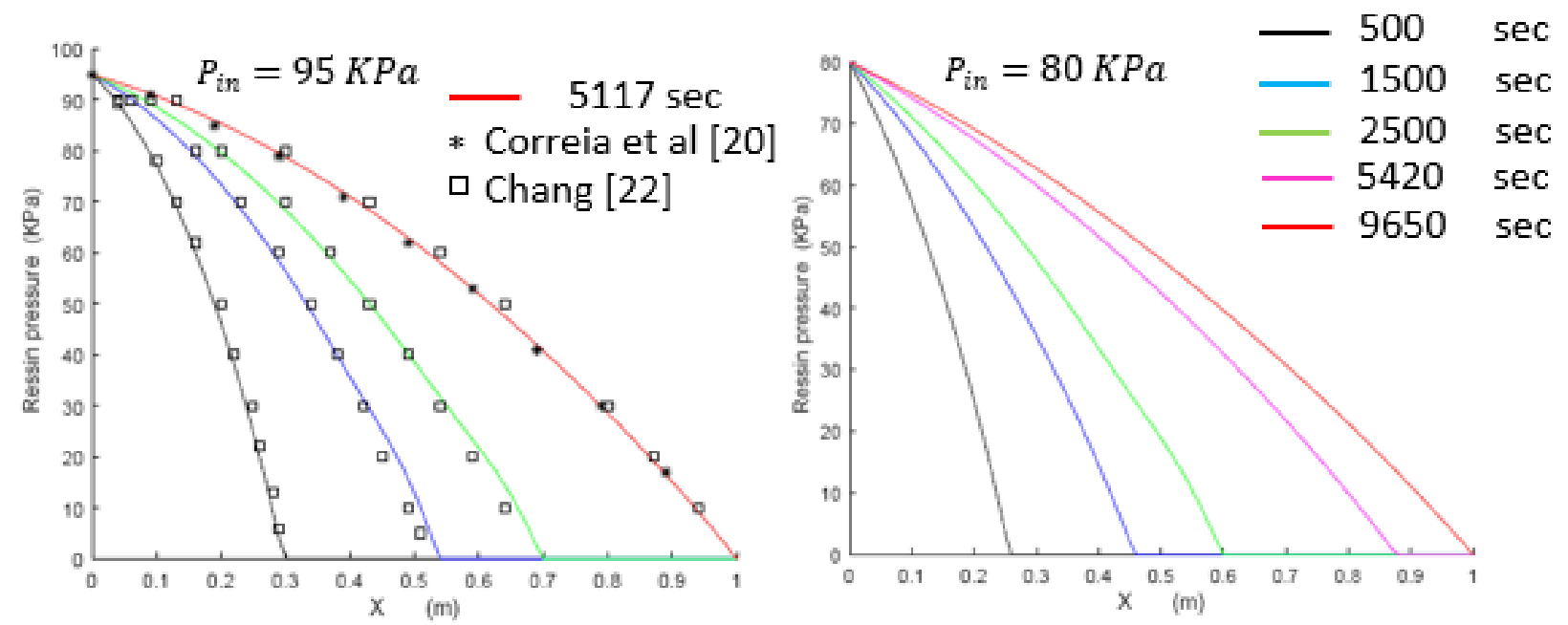

Fig. 7. Resin pressure distribution at various injection pressure in VARI process
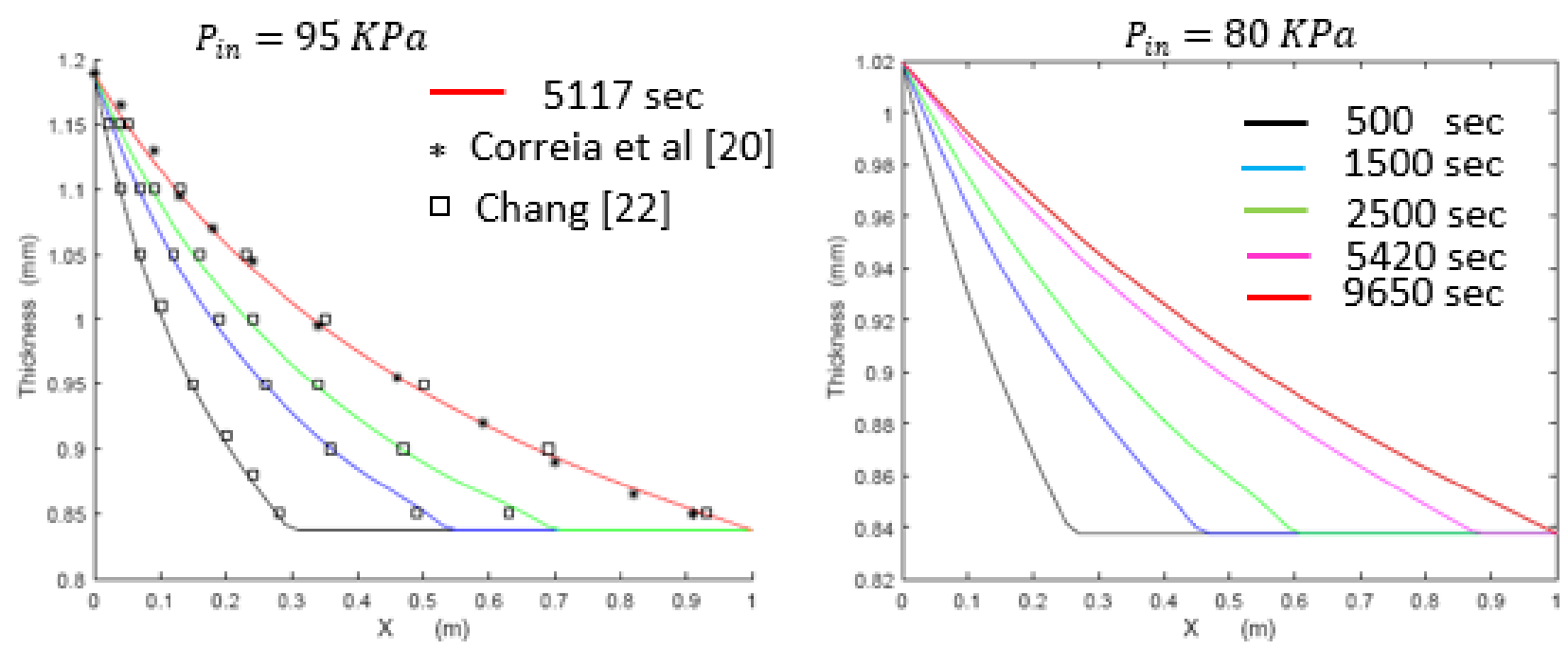

Fig. 8. Preform thickness variation at various injection pressure in VARI process
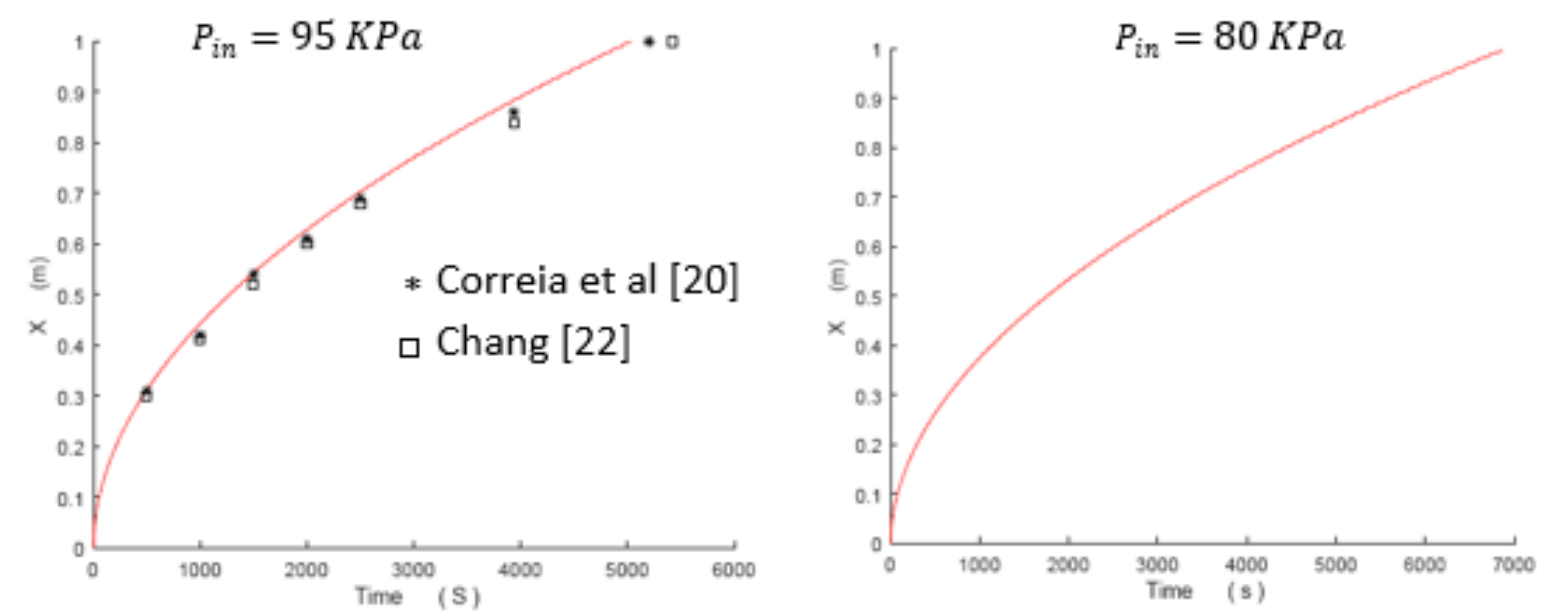

Fig. 9. Resin progression at various injection pressure in VARI process

Figure 10 illustrates the evolution of the resin pressure in the thickness direction. During resin infusion, the external pressure applied on the vacuum bag is carried by the fiber layers and the resin in the wetted zone. While in the dry zone, the external pressure is carried only by the fibers. At the beginning of the infusion phase, the resin pressure at the interface resin film - fabric preform is equal 
to the external pressure applied on the vacuum bag. In this region, the fiber volume fraction is at lowest value. Therefore the resin impregnates quickly this region as shown by the blue curve in the Figure 10. The compaction of the fiber reinforcement changes the distribution behavior of the of resin pressure through the thickness direction. In additon, it leads to decrease its permeability and increase the fiber volume fraction of the fabric preform, as shown in the Figure 11. Therefore, the resin impregnates slowly the fiber reinforcement layers (from blue to red curves). The resin fills entirely the preform at $215 \mathrm{~s}$.

After the preform is fully impregnated, the excess resin is absorbed by the bleeder, and the resin pressure begins to drop. At this stage, the most external pressure is carried by the fibers, which explain the increase in the fiber volume fraction and its uniform distribution in the thickness direction, as illustrated in the Figure 11.

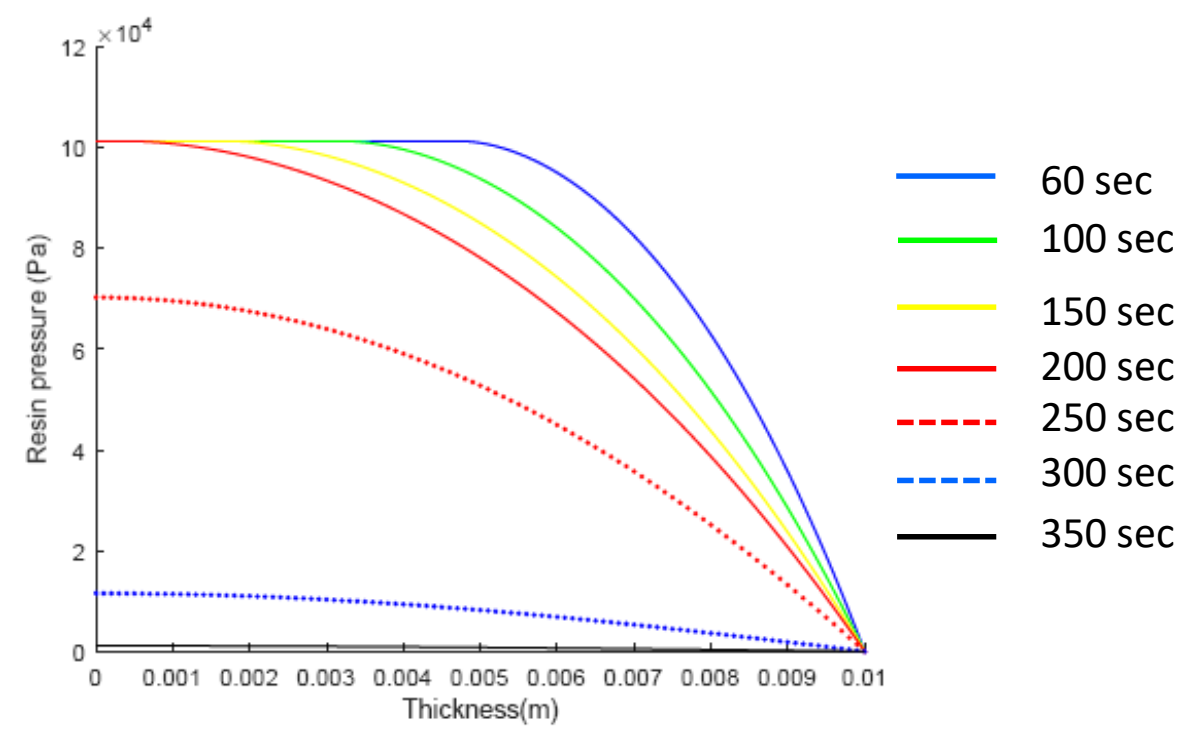

Fig. 10. Resin pressure distribution in the thickness direction

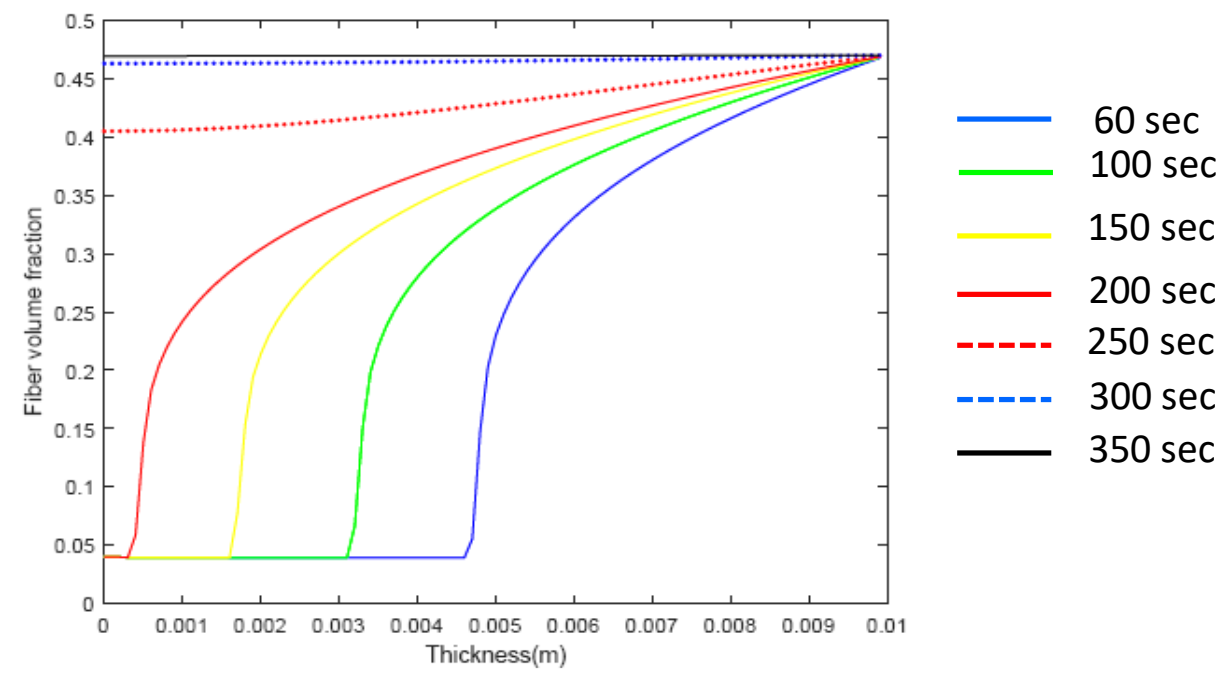

Fig. 11. Fiber volume fraction distribution in the thickness direction

Figure 12 presents the evolution of the filling time as function of the part thickness. The filling time in resin film infusion process increases parabolically with thicker part. 


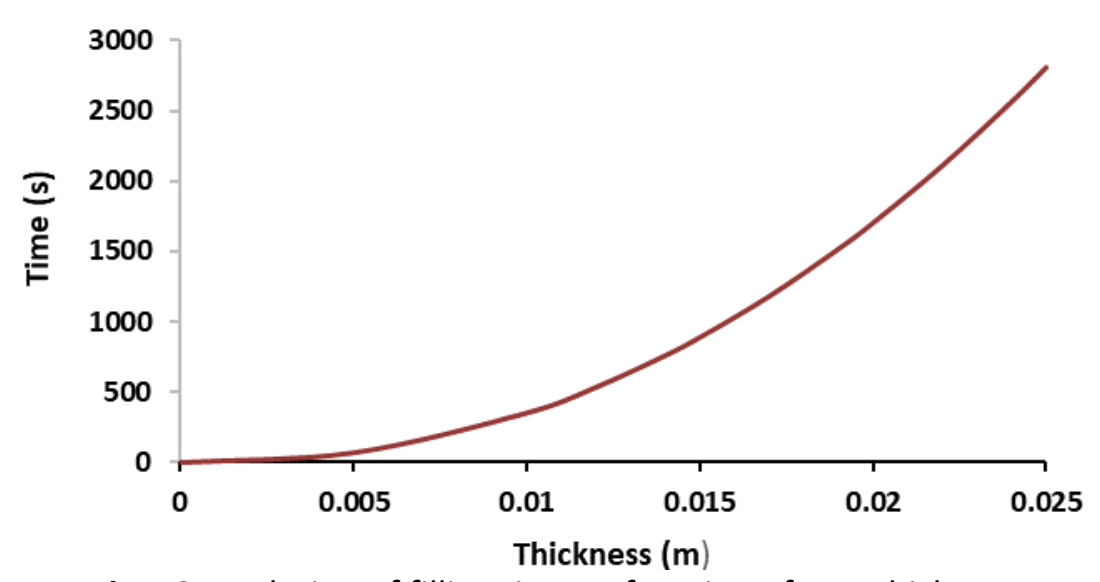

Fig. 12. Evolution of filling time as function of part thickness

\section{Conclusions}

In this paper, a numerical algorithm was proposed to study the influence of the part thickness on the filling time in the resin film infusion process. The numerical scheme was based on the finite difference method. The results obtained have shown that the part thickness has influence on the filling time, and it increases parabolically with the thicker part. Since the melting process of resin film is controlled by temperature, which also affect the resin viscosity and degree of cure, these parameters govern the resin impregnation through fabric preform, a full study should be conducted to better understand the RFI process.

\section{References}

[1] Chang, Chih-Yuan, and Wei-Ru Chen. "Influence of processing variables on quality of unsaturated polyester/E-glass fiber composites manufactured by double-bag progressive compression method." Advances in Mechanical Engineering 10, no. 9 (2018): 1687814018798531. https://doi.org/10.1177/1687814018798531

[2] Achim, V., S. Soukane, R. Gauvin, and F. Trochu. "Simulation of articulated compression resin transfer molding." Proceedings of the 8th flow proc compos mats (2006): 232-330.

[3] Lopatnikov, S., P. Simacek, J. GillespieJr, and S. G. Advani. "A closed form solution to describe infusion of resin under vacuum in deformable fibrous porous media." Modelling and Simulation in Materials Science and Engineering 12, no. 3 (2004): S191. https://doi.org/10.1088/0965-0393/12/3/S09

[4] Ouezgan, Ahmed, Said Adima, Aziz MAZIRI, El Hassan Mallil, and Jamal Echaabi. "A novel design of CRTM mold by using TRIZ separation principles." Acta Technica Napocensis-Series: Applied Mathematics, Mechanics, And Engineering 63, no. 3S (2020). https://doi.org/10.4028/www.scientific.net/KEM.900.3

[5] Sozer, E. M., P. Simacek, and S. G. Advani. "Resin transfer molding (RTM) in polymer matrix composites." In Manufacturing techniques for polymer matrix composites (PMCS), pp. 245-309. Woodhead Publishing, 2012. https://doi.org/10.1533/9780857096258.3.243

[6] Ouezgan, A., S. Adima, A. Maziri, E. Mallil, and J. Echaabi. "An innovative methodology to design LCM Mold for aeronautic and automotive industries." In International TRIZ Future Conference, pp. 472-485. Springer, Cham, 2019. https://doi.org/10.1007/978-3-030-32497-1 37

[7] Yang, Bo, Tianguo Jin, Fengyang Bi, and Jianguang Li. "Modeling the resin flow and numerical simulation of the filling stage for vacuum-assisted resin infusion process." Journal of Reinforced Plastics and Composites 33, no. 21 (2014): 1976-1992. https://doi.org/10.1177/0731684414551039

[8] Liu, Xiao, Yukun Li, Jianjian Zhu, Yishou Wang, and Xinlin Qing. "Monitoring of resin flow front and degree of cure in vacuum-assisted resin infusion process using multifunctional piezoelectric sensor network." Polymer Composites 42, no. 1 (2021): 113-125. https://doi.org/10.1002/pc.25811

[9] Marsh, G. "Resin film infusion-composites cost reducer." Reinforced Plastics(UK) 46, no. 2 (2002): $44-49$. https://doi.org/10.1016/S0034-3617(02)80124-2

[10] Garschke, C., C. Weimer, P. P. Parlevliet, and B. L. Fox. "Out-of-autoclave cure cycle study of a resin film infusion process using in situ process monitoring." Composites Part A: Applied Science and Manufacturing 43, no. 6 (2012): 935-944. https://doi.org/10.1016/i.compositesa.2012.01.003 
[11] Yourdkhani, Mostafa, Wenjiao Liu, Simon Baril-Gosselin, François Robitaille, and Pascal Hubert. "Carbon nanotubereinforced carbon fibre-epoxy composites manufactured by resin film infusion." Composites Science and Technology 166 (2018): 169-175. https://doi.org/10.1016/j.compscitech.2018.01.006

[12] Wang, Ben, Yugang Duan, Zhibo Xin, Xueling Yao, Dilmurat Abliz, and Gerhard Ziegmann. "Fabrication of an enriched graphene surface protection of carbon fiber/epoxy composites for lightning strike via a percolatingassisted resin film infusion method." Composites Science and Technology 158 (2018): 51-60. https://doi.org/10.1016/i.compscitech.2018.01.047

[13] Luo, Haitao, Jie Ding, Zhixiong Huang, and Tao Yang. "Investigation of properties of nano-silica modified epoxy resin films and composites using RFI technology." Composites Part B: Engineering 155 (2018): 288-298. https://doi.org/10.1016/i.compositesb.2018.08.055

[14] Buntain, M. J., and S. Bickerton. "Modeling forces generated within rigid liquid composite molding tools. Part A: Experimental study." Composites Part A: Applied Science and Manufacturing 38, no. 7 (2007): 1729-1741. https://doi.org/10.1016/i.compositesa.2007.01.012

[15] Ouahbi, Tariq, Abdelghani Saouab, Joel Breard, Pierre Ouagne, and Sylvain Chatel. "Modelling of hydro-mechanical coupling in infusion processes." Composites Part A: Applied Science and Manufacturing 38, no. 7 (2007): $1646-1654$. https://doi.org/10.1016/i.compositesa.2007.03.002

[16] Park, Chung Hae, and Abdelghani Saouab. "Analytical modeling of composite molding by resin infusion with flexible tooling: VARI and RFI processes." Journal of composite materials 43, no. 18 (2009): 1877-1900. https://doi.org/10.1177/0021998309341848

[17] Terzaghi, Karl. "Stress conditions for the failure of saturated concrete and rock." In Proceedings-American Society for Testing and Materials, vol. 45, pp. 777-792. 100 BARR HARBOR DR, W CONSHOHOCKEN, PA 19428-2959: AMER SOC TESTING MATERIALS, 1945.

[18] Robitaille, Francois, and Raymond Gauvin. "Compaction of textile reinforcements for composites manufacturing. I: Review of experimental results." Polymer composites 19, no. 2 (1998): 198-216. https://doi.org/10.1002/pc.10091

[19] Carman, Philip Crosbie. "Fluid flow through granular beds." Trans. Inst. Chem. Eng. 15 (1937): 150-166.

[20] Correia, N. C., F. Robitaille, A. C. Long, C. D. Rudd, P. Šimáček, and S. G. Advani. "Analysis of the vacuum infusion moulding process: I. Analytical formulation." Composites Part A: Applied Science and Manufacturing 36, no. 12 (2005): 1645-1656. https://doi.org/10.1016/i.compositesa.2005.03.019

[21] Song, Young Seok, and Jae Ryoun Youn. "Numerical investigation on flow through porous media in the post-infusion process." Polymer Composites 30, no. 8 (2009): 1125-1131. https://doi.org/10.1002/pc.20668

[22] Chang, Chih-Yuan. "Numerical study of filling strategies in vacuum assisted resin transfer molding process." Journal of Polymer Engineering 35, no. 5 (2015): 493-501. https://doi.org/10.1515/polyeng-2014-0237 